Supplement of The Cryosphere, 10, 1547-1570, 2016

http://www.the-cryosphere.net/10/1547/2016/

doi:10.5194/tc-10-1547-2016-supplement

(C) Author(s) 2016. CC Attribution 3.0 License.

(c) (1)

Supplement of

\title{
An ice-sheet-wide framework for englacial attenuation from ice-penetrating radar data
}

\section{T. M. Jordan et al.}

Correspondence to: T. M. Jordan (tom.jordan@bris.ac.uk) and J. L. Bamber (j.bamber@bris.ac.uk)

The copyright of individual parts of the supplement might differ from the CC-BY 3.0 licence. 
Manuscript prepared for The Cryosphere

with version 2015/04/24 7.83 Copernicus papers of the $\mathrm{LT}_{\mathrm{E}} \mathrm{X}$ class copernicus.cls.

Date: 19 July 2016

\title{
Supplementary material for: An ice sheet wide framework for englacial attenuation from ice penetrating radar data
}

\author{
T. M. Jordan ${ }^{1}$, J. L. Bamber ${ }^{1}$, C. N. Williams ${ }^{1}$, J. D. Paden ${ }^{2}$, M. J. Siegert ${ }^{3}$, \\ P. Huybrechts ${ }^{4}$, O. Gagliardini ${ }^{5}$, and F. Gillet-Chaulet ${ }^{6}$ \\ ${ }^{1}$ Bristol Glaciology Centre, School of Geographical Sciences, University of Bristol, Bristol, UK. \\ ${ }^{2}$ Center for Remote Sensing of Ice sheets, University of Kansas, Lawrence, USA. \\ ${ }^{3}$ Grantham Institute and Earth Science and Engineering, Imperial College, University of London, \\ London, UK. \\ ${ }^{4}$ Earth System Science and Departement Geografie, Vrije Universiteit Brussel, Brussels, Belgium. \\ ${ }^{5}$ Le Laboratoire de Glaciologie et Géophysique de l'Environnement, University Grenoble Alpes, \\ Grenoble, France. \\ ${ }^{6}$ Le Laboratoire de Glaciologie et Géophysique de l'Environnement, Centre National de la \\ Recherche Scientifique, Grenoble, France.
}

In this supplementary material we firstly discuss the temperature sensitivity of the algorithm sample region (Sect.S1), and the tuning of the sample region tolerance (Sect. S2), which both accompany Sect 2.5 in the main article. We then illustrate the ice sheet wide properties of the algorithm using the SICOPOLIS temperature field as an input (Sect. S3], as was shown for the GISM temperature field in Sect. 3.1. The convergence of the attenuation solution in drainage basins other than the SE GrIS (Sect. 3.2 in the main article) is then discussed (Sect.S4). Finally, we provide evidence of algorithm repeatability for independently analysed field campaign data (Sect. [S5], which expands upon Sect. 3.4 in the main article.

\section{S1 Temperature sensitivity of the algorithm sample regions}

Maps for the target window vectors, $R_{1}-R_{4}$, using the SICOPOLIS temperature field are shown in Fig. S1 These are equivalent to Fig. 7 in the main text for the GISM temperature field, and a target window vector difference plot for the two temperature fields is shown in Fig. S2 It is evident that both temperature fields share the same ice sheet wide trend that the target window vectors are larger in the interior of the ice sheet. Generally, the GISM temperature field has larger window vectors than SICOPOLIS toward the ice margins. An explanation for this trend is that the horizontal gradient in the absolute values $\langle\hat{B}\rangle$ (which is approximately equivalent to depth-averaged temperature) are larger toward the margins for the SICOPOLIS temperature field (also refer to Fig. 5. in main article). The target windows vectors are more sensitive to temperature field, (in terms of absolute differences in target window vector length), in the northern interior of the GrIS. This is thought to arise because 
the segment approximation that is used in the target windowing procedure becomes more sensitive in colder ice, where there is a smaller horizontal gradient in $\langle\hat{B}\rangle$. Future refinements to the algorithm could therefore consider developing a more refined target windowing procedure for the sample region in colder ice

\section{S2 Tuning the tolerance of the algorithm sample region}

A free parameter in our sample region windowing method is the RMS tolerance metric that is used to define the target window vectors and boundaries, (refer to Appendix C). If the RMS tolerance is too small, then the ice thickness range is insufficient to discriminate an attenuation trend and the solution accuracy and related coverage regions are reduced. This point is illustrated by a comparison of algorithm coverage regions for $\mathrm{RMS}=1 \mathrm{~dB} \mathrm{~km}^{-1}$ and $\mathrm{RMS}=0.5 \mathrm{~dB} \mathrm{~km}^{-1}$ in Fig. $\mathrm{S} 3$. The lower coverage for $\mathrm{RMS}=0.5 \mathrm{~dB} \mathrm{~km}^{-1}$ arises primarily due to lower $r_{\left[P^{C}\right]}^{2}$ values. Additionally, due to the smaller sample region windows for $\mathrm{RMS}=0.5 \mathrm{~dB} \mathrm{~km}^{-1}$ less of the grid points meet the minimum threshold of 20 data points.

As the RMS tolerance is increased, the sample regions will contain individual ice columns with a greater range of depth-averaged attenuation rates. This is undesirable for a bed-returned power attenuation algorithm, which either assumes: (i) local constancy or, (ii) makes a local attenuation correction. For algorithms that assume local constancy, the degree of systematic underestimation the attenuation rate (described in Sect. 2.6 and Fig. 8) is predicted to increase with window size/RMS tolerance. For the local attenuation correction variant of the bed-returned power method described here, the local attenuation correction, Eq. (9), increases with the RMS tolerance. It therefore follows that greater RMS tolerance values are more susceptible to bias from the Arrhenius temperature model input. Subsequently, we suggest that the desired level of solution accuracy should inform the choice the RMS tolerance. As discussed in the main article, the desired attenuation loss accuracy for basal melt discrimination is $\sim 5 \mathrm{~dB}$. If this is rescaled by ice thickness for a sample region in the interior of the ice sheet (mean ice thickness $\sim 2500 \mathrm{~m}$ ), this results in a desired attenuation rate accuracy $\sim 1$ $\mathrm{dB} \mathrm{km}^{-1}$. This choice is consolidated by our estimates of attenuation rate solution accuracy in Sect. 3.4 , and Sect. S5 which are similar to the predicted range of values over which the ice columns are sampled.

\section{S3 Ice sheet wide properties using the SICOPOLIS temperature field}

The ice sheet wide properties of the radar algorithm using the SICOPOLIS temperature field are shown in Fig. S4 and are equivalent to Fig. 9 in the main article for GISM. The map for $r_{\left[P^{C}\right]}^{2}$ for SICOPLOLIS is very similar to GISM, and supports the view that the algorithm has greater utility for identifying an attenuation trend in regions of rougher basal topography and where the absolute values of the attenuation rate are higher. The regions of high $r_{[\hat{R}]}^{2} /$ low $r_{\text {ratio }}^{2}$ for the two temperature 
fields are less well correlated. For the reasons discussed in Sect. 2.7 it is difficult to establish whether, for either temperature field, the majority of these regions correspond to: (i) true variation in the basal reflector with ice thickness, (ii) a strong bias in the ice sheet model temperature field. However, for regions where there is ice core temperature data available it is possible to predict which scenario is more likely. Notably, for the region surrounding the NEEM and Camp Century ice cores in North West Greenland, the GISM temperature field is very close to the core data (Fig. S55). This is therefore suggestive that the regions of high $r_{[\hat{R}]}^{2}$ in Fig. 9 correspond to a true variation in the basal reflector with ice thickness.

As described in Sect. 2.6, a minimum of 20 IPR (along-track averaged) measurements within each target window is set as a threshold for including a grid cell in the linear regression procedure. Due to the generally smaller target window vectors for the SICOPOLIS temperature field toward the ice margins, Fig. S2, there are more grid cells that fall below this threshold if this temperature field is used as in input. This effect is particularly apparent along the western ice margin where the maps for SICOPOLIS input in Fig. S4 are non-continuous.

\section{S4 Demonstration of solution convergence in other drainage basins}

We observe qualitatively similar attenuation solution behavior in drainage basins 3,5,6 (southern and eastern Greenland) to that described for drainage basin 4 in the main article. In all these basins we observe algorithm solution convergence and an associated reduction in the solution bias from the Arrhenius model input. An example of the attenuation rate solution differences for drainage basin 6 (the SW GrIS) is shown in Fig. S6 1 , with the radar-inferred distribution being approximately normally distributed about zero, $\left(\mu \pm \sigma=-0.18 \pm 1.56 \mathrm{~dB} \mathrm{~km}^{-1}\right)$, and the Arrhenius model input having a mean systematic bias of $\mu=-1.66 \mathrm{~dB} \mathrm{~km}^{-1}$. In drainage basins 1,2,7,8 (northern and western Greenland) we do not observe analogous solution convergence, (in the sense of normally distributed difference distribution for the radar-inferred values). We do, however, typically see a reduction in the mean systematic bias of the attenuation rate solution, relative to the Arrhenius model input. For example, in drainage basin 8 (the NW GrIS), the Arrhenius model mean attenuation rate bias is $\mu=-$

$803.62 \mathrm{~dB} \mathrm{~km}^{-1}$, whereas the radar-inferred value is $\mu=-2.62 \mathrm{~dB} \mathrm{~km}^{-1}$ (Fig. S6b). An explanation for why we observe solution convergence in some basins but not others is thought to relate to the temperature dependence of the target windows (Sect. S1, which is generally higher in the northern interior. In turn, this results in different IPR data being sampled for the different temperature field inputs.

\section{S5 Repeatability and uncertainty for independently analysed field seasons}

In Sect. 3.4. we proposed that the attenuation solution uncertainty can be measured by: (i) solution variation for different input temperature fields, (ii) solution variation for independently analysed field 
seasons (with a fixed temperature field input). Since, for equivalent algorithm settings, the solution variation for different input temperature fields is slightly higher, we focused upon this in the main article as it gives a better overall indicator of solution uncertainty.

A full summary of attenuation rate solution variation for different field season pairs is shown in Table S1 and an example of the distributions and mutual coverage regions is shown in Fig. S7. The mutual coverage regions occur where there are regions of intersecting flight tracks (Fig. 1a). As these overlap regions are quite small, we considered the GrIS as a whole when measuring solution variation. The general relationship between solution variation (as measured by the standard deviation of the solution difference distribution) and algorithm coverage (as measure by the frequency of grid cells that contain IPR data), is similar to the case for different input temperature fields. For $(\alpha, \beta)=$ $(0.60,0.80)$, the mean standard deviation aggregated over the different field season combinations is $1.29 \mathrm{~dB} \mathrm{~km}^{-1}$. This supports the conclusion in the main paper that this algorithm quality setting represents sufficient accuracy for defining a coverage region for discrimination of basal melt from the reflection values. 


\section{References}

Macgregor, J. A., Li, J., Paden, J. D., Catania, G. A., and Clow, G. D.: Radar attenuation and temperature within the Greenland Ice Sheet, Journal of Geophysical Research: Earth Surface, 120, 983-1008, doi:10.1002/2014JF003418, 2015.

Weertman, J.: Comparison between measured and theoretical temperature profiles of the Camp Century, Greenland, Borehole, Journal of Geophysical Research, 73, 2691-2700, 1968. 

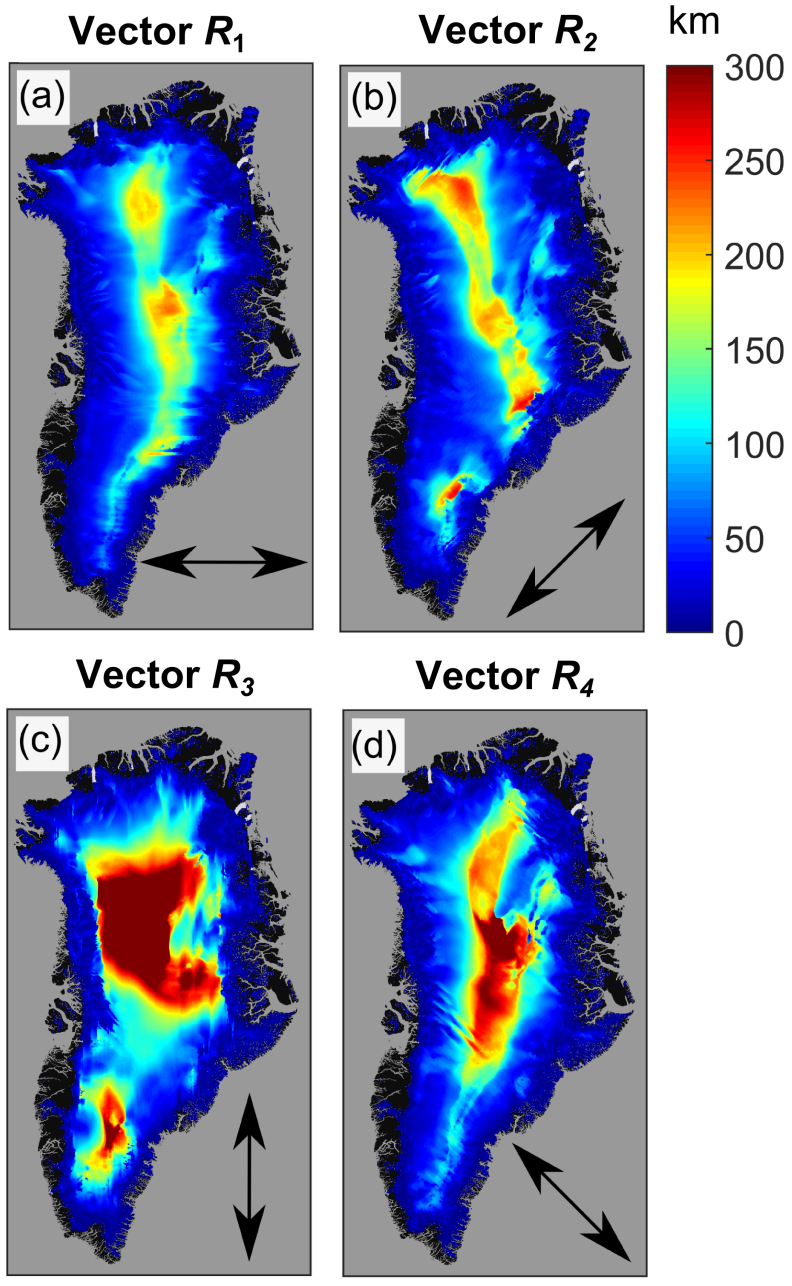

\section{Vector $\boldsymbol{R}_{\mathbf{4}}$}

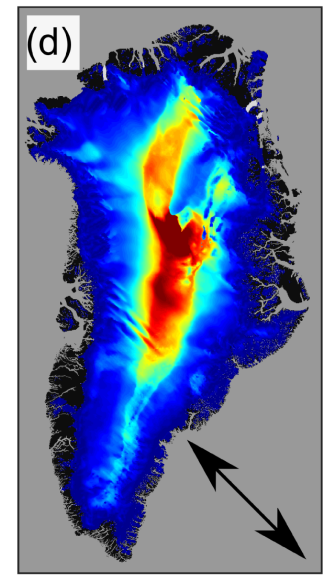

Figure S1. Maps for target window radi vector length using the SICOPOLIS temperature field. (a) Vector $R_{1}$, (b) Vector $R_{2}$, (c) Vector $R_{3}$, (d) Vector $R_{4}$. The orientation of each radi vector is shown in each subplot. 

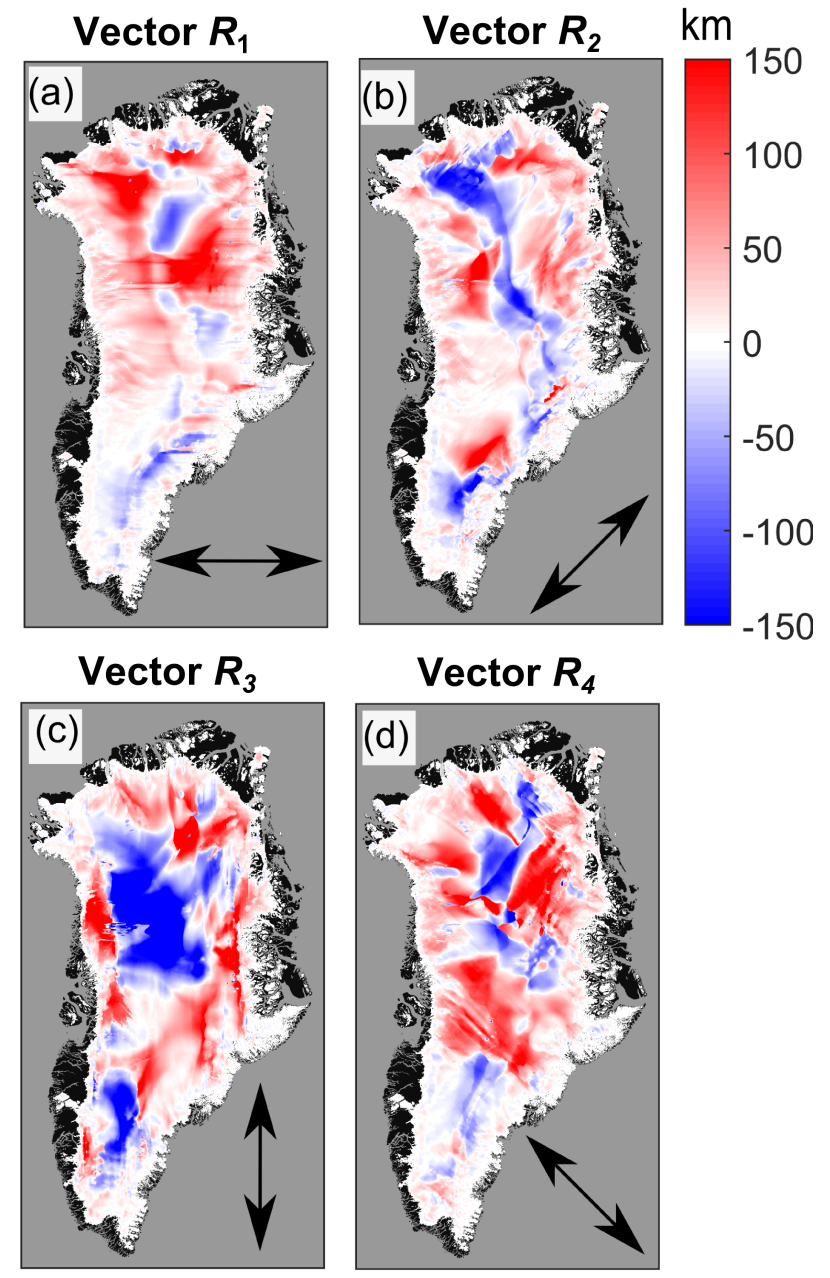

Figure S2. Difference maps for the length of target window radi vectors (GISM-SICOPOLIS). (a) Vector $R_{1}$, (b) Vector $R_{2}$, (c) Vector $R_{3}$, (d) Vector $R_{4}$. The orientation of each radi vector is shown in each subplot. 
Coverage: RMS $=1 \mathrm{~dB} \mathrm{~km}^{-1}$

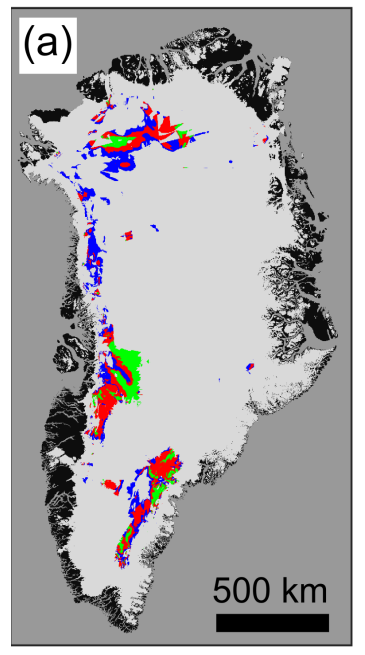

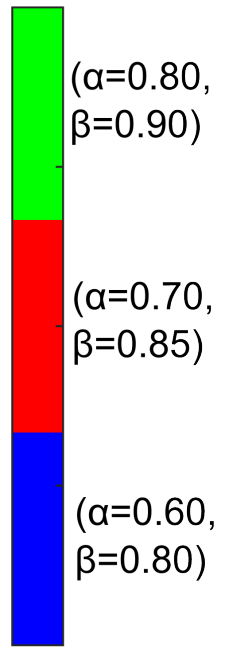

Coverage: $\mathrm{RMS}=0.5 \mathrm{~dB} \mathrm{~km}^{-1}$

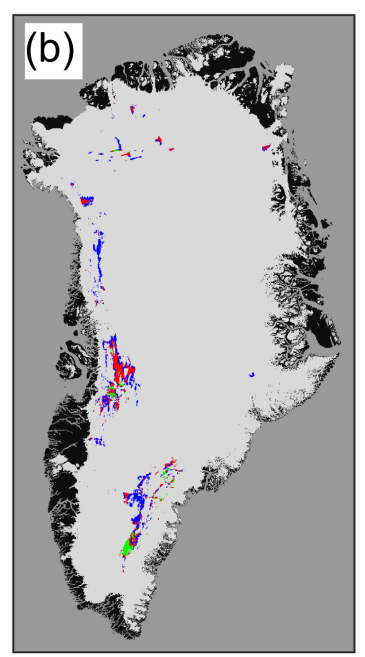

$(\alpha=0.80$, $\beta=0.90$ )

$(\alpha=0.70$,

$\beta=0.85$ )

$(\alpha=0.60$,

$\beta=0.80$ )

Figure S3. Example of algorithm coverage regions for different window tolerances. (a) $\mathrm{RMS}=1 \mathrm{~dB} \mathrm{~km}^{1}$, (b) RMS $=0.5 \mathrm{~dB} \mathrm{~km}^{1}$. Both plots are for the $2011 \mathrm{P} 3$ field season data using the GISM temperature field. 


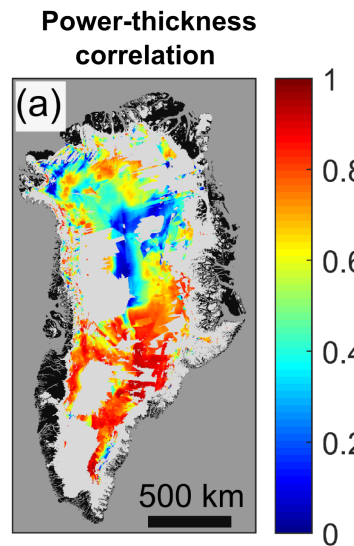

\section{Power-reflectivity} correlation
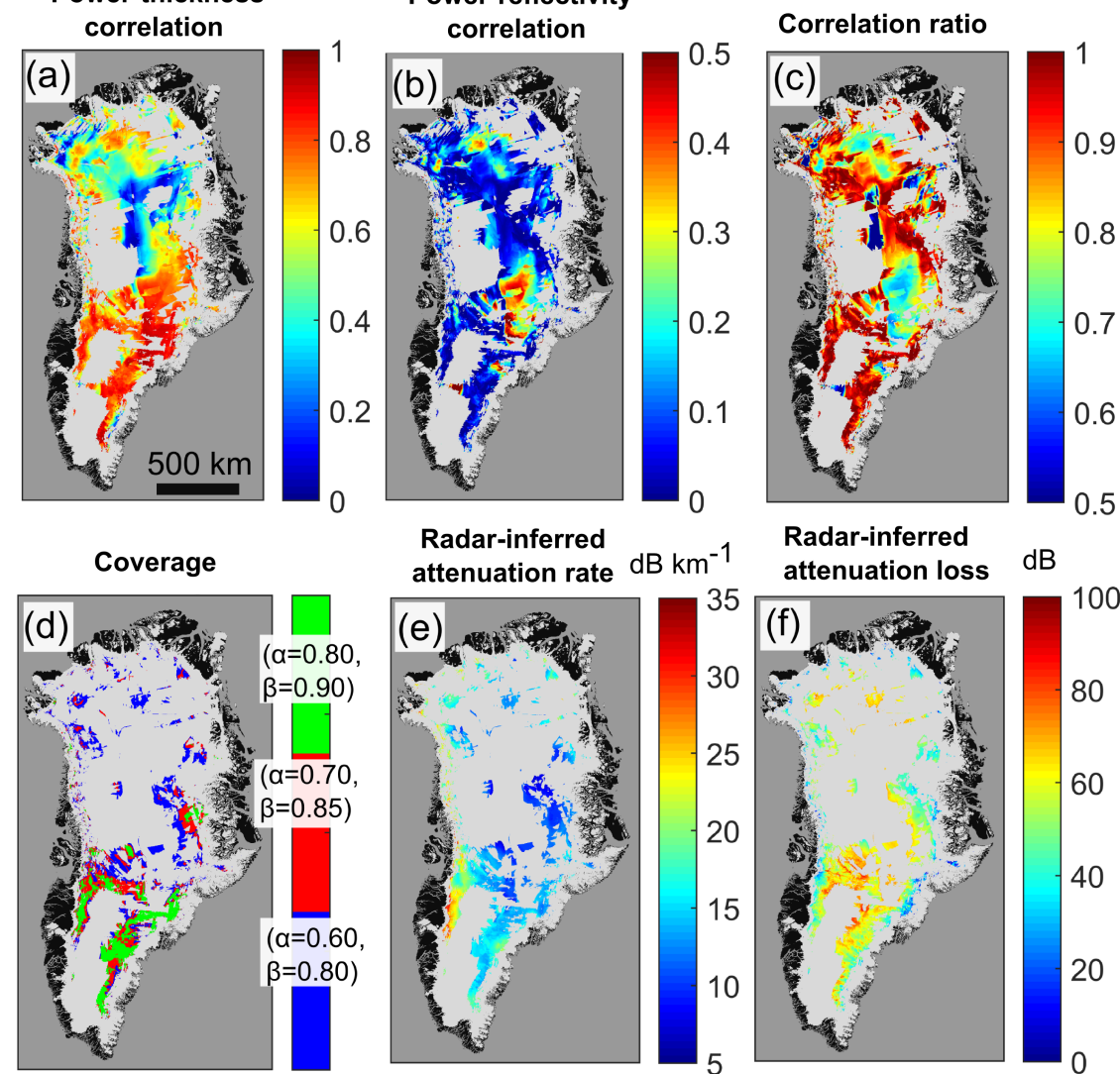

$\mathrm{dB}$
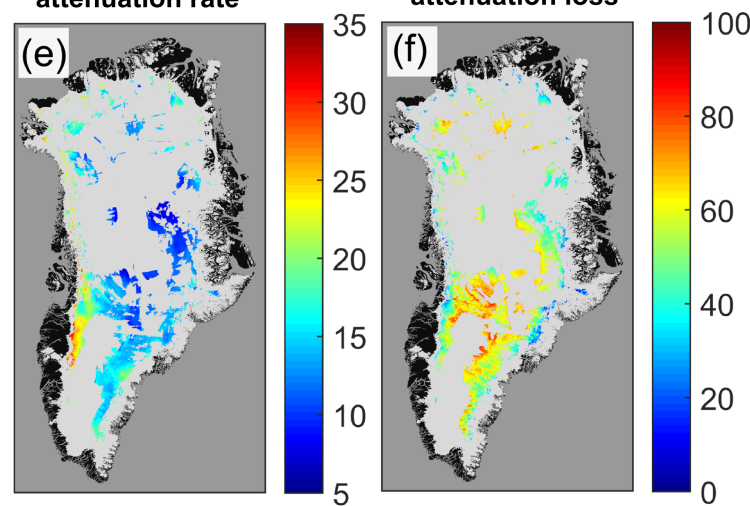

Figure S4. Ice sheet wide properties of the radar algorithm using the SICOPOLIS temperature field. (a) Powerthickness correlation, $r_{\left[P^{C}\right]}^{2}$. (b) Arrhenius reflection coefficient-thickness correlation, $r_{[\hat{R}]}^{2}$. (c) Correlation ratio, $r_{\text {ratio }}^{2}$. (d) Coverage for three thresholds (green is a subset of red and red is a subset of blue). (e) Radarinferred attenuation rate, $\left\langle B\left(T_{\mathrm{SIC}}\right)>\right.$, for $(\alpha, \beta)=(0.60,0.80)$. (f) Radar-inferred attenuation loss, $\left[L\left(T_{\mathrm{SIC}}\right)\right]$, for $(\alpha, \beta)=(0.60,0.80)$. 

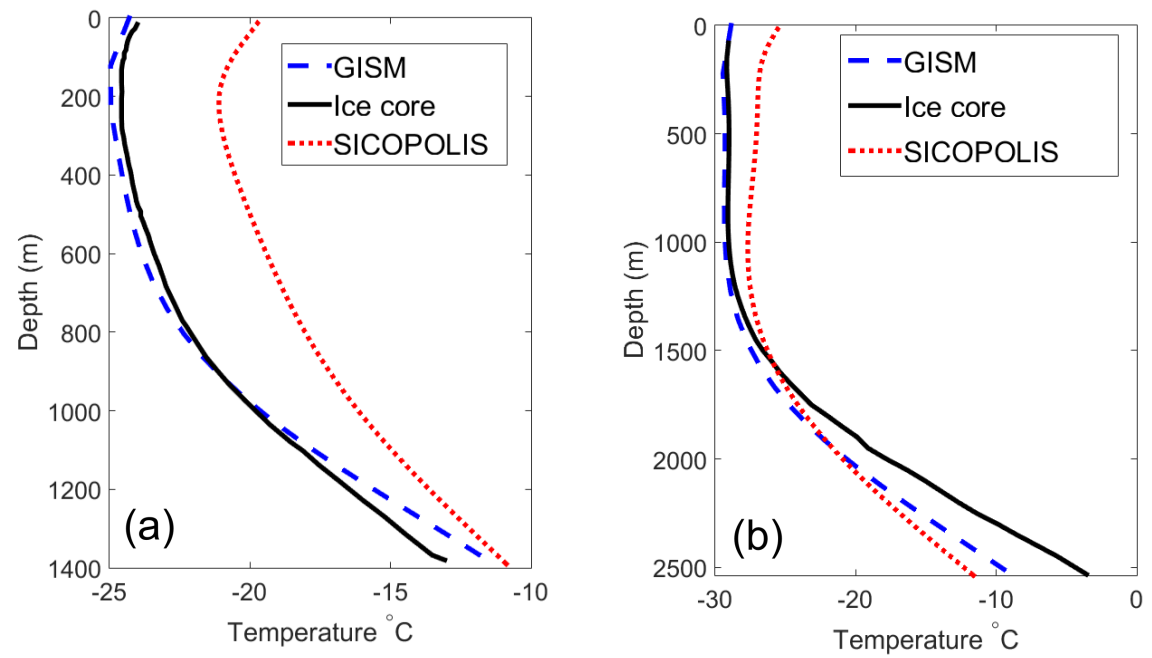

Figure S5. Vertical temperature profiles. (a) Camp Century (Weertman 1968), (b) NEEM (Macgregor et al. 2015).
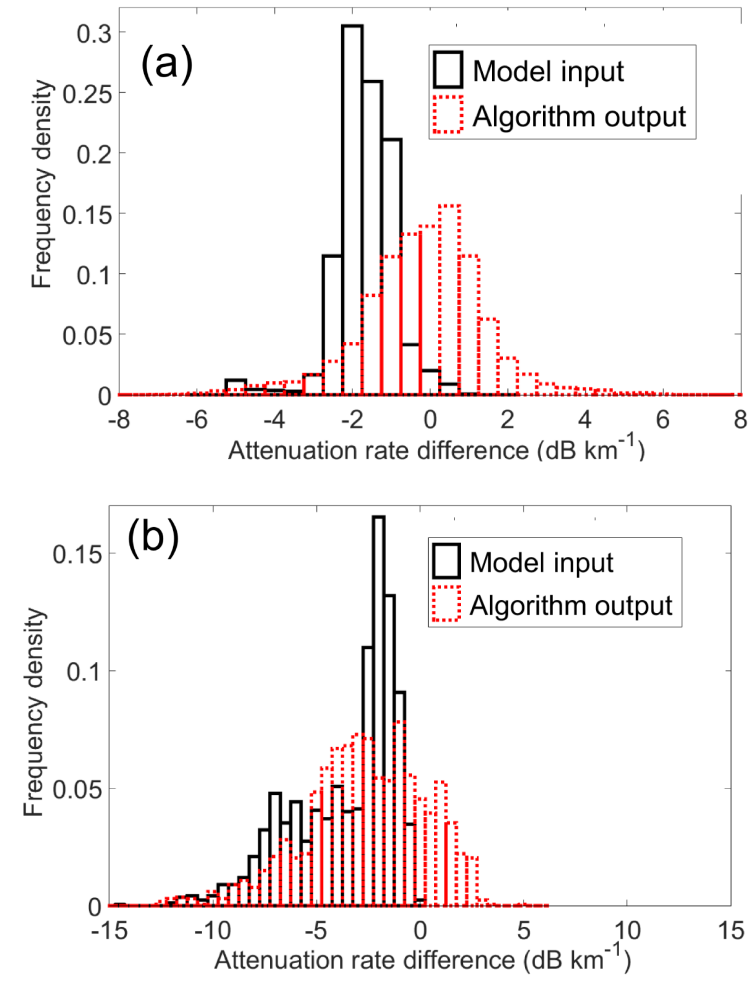

Figure S6. Attenuation rate difference distributions. (a) SW Greenland (drainage basin 6 in Fig. 1), (b) NW Greenland (drainage basin 8 in Fig. 1). 
Table S1. Summary of attenuation rate solution variation for independently analysed field season pairs.

\begin{tabular}{|c|c|c|c|c|}
\hline Season pair & Algorithm settings & Mean, $\mu,\left(\mathrm{dB} \mathrm{km}^{-1}\right)$ & Standard deviation, $\sigma,\left(\mathrm{dB} \mathrm{km}^{-1}\right)$ & Frequency, N. \\
\hline \multirow[t]{6}{*}{$2012-2011$} & $T_{\mathrm{GISM}}:(\alpha, \beta)=(0.60,0.80)$ & -0.28 & 1.34 & 9869 \\
\hline & $T_{\mathrm{GISM}}:(\alpha, \beta)=(0.70,0.85)$ & -0.11 & 1.08 & 5522 \\
\hline & $T_{\mathrm{GISM}}:(\alpha, \beta)=(0.80,0.90)$ & 0.26 & 0.65 & 953 \\
\hline & $T_{\mathrm{SIC}}:(\alpha, \beta)=(0.60,0.80)$ & -0.71 & 1.71 & 6339 \\
\hline & $T_{\mathrm{SIC}}:(\alpha, \beta)=(0.70,0.85)$ & -0.81 & 1.36 & 4164 \\
\hline & $T_{\text {SIC }}:(\alpha, \beta)=(0.80,0.90)$ & -0.50 & 1.01 & 1371 \\
\hline \multirow[t]{6}{*}{ 2013-2011 } & $T_{\mathrm{GISM}}:(\alpha, \beta)=(0.60,0.80)$ & -0.13 & 1.46 & 6698 \\
\hline & $T_{\mathrm{GISM}}:(\alpha, \beta)=(0.70,0.85)$ & -0.26 & 1.03 & 3584 \\
\hline & $T_{\mathrm{GISM}}:(\alpha, \beta)=(0.80,0.90)$ & 0.181 & 0.62 & 521 \\
\hline & $T_{\mathrm{SIC}}:(\alpha, \beta)=(0.60,0.80)$ & -0.73 & 1.42 & 5330 \\
\hline & $T_{\mathrm{SIC}}:(\alpha, \beta)=(0.70,0.85)$ & -0.84 & 1.14 & 3509 \\
\hline & $T_{\text {SIC }}:(\alpha, \beta)=(0.80,0.90)$ & -1.09 & 0.85 & 953 \\
\hline \multirow[t]{6}{*}{ 2014-2011 } & $T_{\mathrm{GISM}}:(\alpha, \beta)=(0.60,0.80)$ & 0.05 & 1.55 & 10036 \\
\hline & $T_{\mathrm{GISM}}:(\alpha, \beta)=(0.70,0.85)$ & -0.18 & 1.12 & 5045 \\
\hline & $T_{\mathrm{GISM}}:(\alpha, \beta)=(0.80,0.90)$ & 0.57 & 0.85 & 533 \\
\hline & $T_{\mathrm{SIC}}:(\alpha, \beta)=(0.60,0.80)$ & -0.22 & 1.48 & 7934 \\
\hline & $T_{\mathrm{SIC}}:(\alpha, \beta)=(0.70,0.85)$ & -0.38 & 1.18 & 5614 \\
\hline & $T_{\mathrm{SIC}}:(\alpha, \beta)=(0.80,0.90)$ & -0.16 & 1.02 & 1765 \\
\hline \multirow[t]{6}{*}{ 2013-2012 } & $T_{\mathrm{GISM}}:(\alpha, \beta)=(0.60,0.80)$ & 0.33 & 1.06 & 6557 \\
\hline & $T_{\mathrm{GISM}}:(\alpha, \beta)=(0.70,0.85)$ & 0.33 & 0.92 & 4913 \\
\hline & $T_{\mathrm{GISM}}:(\alpha, \beta)=(0.80,0.90)$ & 0.38 & 0.44 & 343 \\
\hline & $T_{\mathrm{SIC}}:(\alpha, \beta)=(0.60,0.80)$ & 0.10 & 1.02 & 5272 \\
\hline & $T_{\mathrm{SIC}}:(\alpha, \beta)=(0.70,0.85)$ & 0.16 & 0.85 & 3319 \\
\hline & $T_{\text {SIC }}:(\alpha, \beta)=(0.80,0.90)$ & 0.27 & 0.59 & 1202 \\
\hline \multirow[t]{6}{*}{ 2014-2012 } & $T_{\mathrm{GISM}}:(\alpha, \beta)=(0.60,0.80)$ & 0.53 & 1.26 & 10195 \\
\hline & $T_{\mathrm{GISM}}:(\alpha, \beta)=(0.70,0.85)$ & 0.33 & 0.92 & 4913 \\
\hline & $T_{\mathrm{GISM}}:(\alpha, \beta)=(0.80,0.90)$ & 0.38 & 0.65 & 343 \\
\hline & $T_{\mathrm{SIC}}:(\alpha, \beta)=(0.60,0.80)$ & 0.32 & 1.23 & 7015 \\
\hline & $T_{\mathrm{SIC}}:(\alpha, \beta)=(0.70,0.85)$ & 0.35 & 1.12 & 4838 \\
\hline & $T_{\mathrm{SIC}}:(\alpha, \beta)=(0.80,0.90)$ & 0.32 & 1.23 & 586 \\
\hline \multirow[t]{6}{*}{$2014-2013$} & $T_{\mathrm{GISM}}:(\alpha, \beta)=(0.60,0.80)$ & 0.02 & 0.98 & 6350 \\
\hline & $T_{\mathrm{GISM}}:(\alpha, \beta)=(0.70,0.85)$ & 0.11 & 0.59 & 3952 \\
\hline & $T_{\mathrm{GISM}}:(\alpha, \beta)=(0.80,0.90)$ & -0.03 & 0.32 & 540 \\
\hline & $T_{\mathrm{SIC}}:(\alpha, \beta)=(0.60,0.80)$ & 0.25 & 1.00 & 5371 \\
\hline & $T_{\mathrm{SIC}}:(\alpha, \beta)=(0.70,0.85)$ & 0.21 & 0.79 & 3889 \\
\hline & $T_{\mathrm{SIC}}:(\alpha, \beta)=(0.80,0.90)$ & 0.40 & 0.32 & 1353 \\
\hline
\end{tabular}




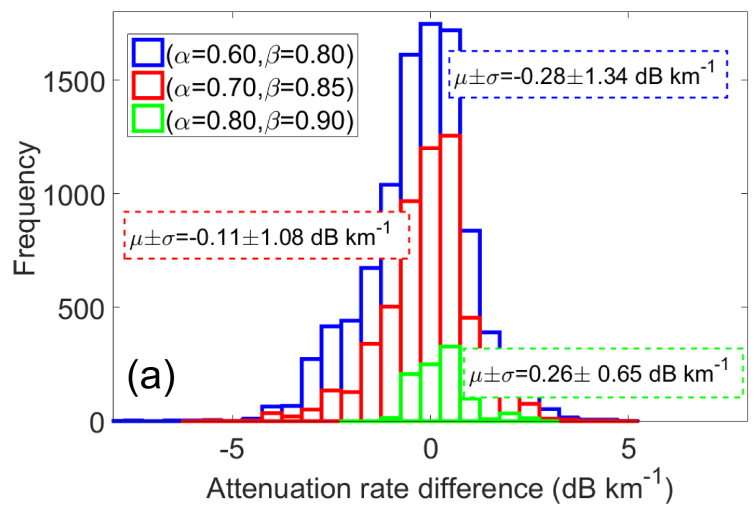

Coverage

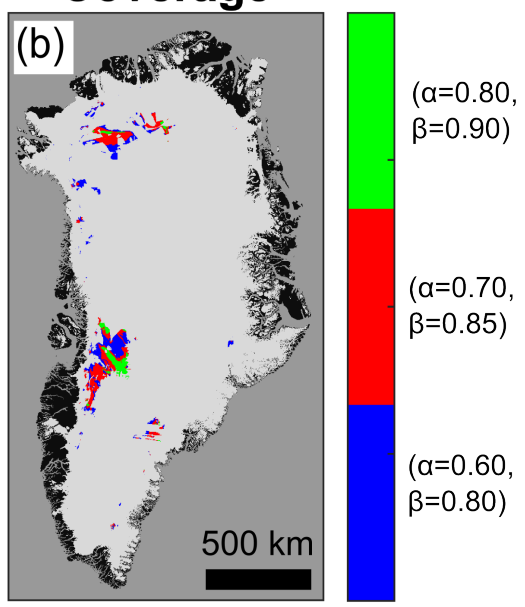

Figure S7. (a) Example of attenuation rate difference distributions for independently analysed field seasons (2012 P3-2011 P3). (b) Coverage overlap region. 